Meta

Journal des traducteurs

Translators' Journal

\title{
Advertising in Translation: English vs. Greek
}

\section{Maria Sidiropoulou}

Volume 43, numéro 2, juin 1998

URI : https://id.erudit.org/iderudit/004141ar

DOI : https://doi.org/10.7202/004141ar

Aller au sommaire du numéro

Éditeur(s)

Les Presses de l'Université de Montréal

ISSN

0026-0452 (imprimé)

1492-1421 (numérique)

Découvrir la revue

Citer cet article

Sidiropoulou, M. (1998). Advertising in Translation: English vs. Greek. Meta, 43(2), 191-204. https://doi.org/10.7202/004141ar

\section{Résumé de l'article}

Pour analyser la publicité, il faut comprendre la culture du destinataire, le rôle de la publicité pouvant être diversement perçu à travers les cultures. En effet, les stratégies et techniques de persuasion mises en œuvre dans le discours publicitaire doivent être adaptées en fonction du contexte culturel du public cible. L'étude de 55 annonces bilingues grec-anglais montre que le traducteur doit tenir compte tout aussi bien des conventions d'écriture (en fonction des genres) que des stratégies de communication utilisées.
Ce document est protégé par la loi sur le droit d'auteur. L'utilisation des services d’Érudit (y compris la reproduction) est assujettie à sa politique d'utilisation que vous pouvez consulter en ligne.

https://apropos.erudit.org/fr/usagers/politique-dutilisation/ 


\title{
ADVERTISING IN TRANSLATION: ENGLISH VS. GREEK ${ }^{1}$
}

\author{
MARIA SIDIROPOULOU \\ University of Athens, Athens, Greece
}

\begin{abstract}
Résumé
Pour analyser la publicité, il faut comprendre la culture du destinataire, le rôle de la publicité pouvant être diversement perçu à travers les cultures. En effet, les stratégies et techniques de persuasion mises en œuvre dans le discours publicitaire doivent être adaptées en fonction du contexte culturel du public cible. L'étude de 55 annonces bilingues grec-anglais montre que le traducteur doit tenir compte tout aussi bien des conventions d'écriture (en fonction des genres) que des stratégies de communication utilisées.
\end{abstract}

\begin{abstract}
The role of advertising can be perceived quite differently across cultures. Analysts, therefore, are advised to approach advertisements with some understanding of the expectations in a particular culture (Rotzoll 1985). Such advice is particularly important in translating advertisements since the various strategies and techniques employed for persuasion have to be adjusted in the target culture in order for the intended perlocutionary effect to be achieved. The 55 English-Greek advertisement pairs examined in this research indicate that the translator should be sensitive not only to conventions applying across genres in a particular culture, but also to conventions associated with genre-internal variation, as 'soft-sell' and 'hard-sell' approaches in advertising are shown to require different types of interferences, in the translation process, for appropriateness to be achieved.
\end{abstract}

\section{INTRODUCTION}

Advertising - among schools, government and news media - has been considered an 'awareness institution' in that it shapes people's basic concepts of how the world operates and what kinds of lives are worth living. No matter what effect advertising may have on general consumer demand for advertised goods, the linguistic choices are carefully made to appeal to the consumer's preferences and potential needs. As cultural groups are differentially vulnerable to particular persuasion strategies, the content and linguistic choices in advertising vary cross-culturally. This is expected to be reflected in the translation of advertisements. The choice of information modified in the 55 EnglishGreek advertisement pairs examined reveals differences in the cultural consumer's role and profile in the social situation. The way this cross-cultural variation is realized has implications on the translation process and the translator's role.

Advertisements are 'one-way' discourses and are said to create 'pseudocommunication'. They differ from 'two-way discourses' or 'genuine communication' (Fairclough 1989: 203), where producer and interpreter roles alternate, in that, here, there is no negotiation of meaning between sender and addressee.

The data examined indicate differences between source and target versions of advertisements, with reference to (a) the content and content organization, and (b) the linguistic devices constructing a particular type of sender-addressee relationship. This distinction in the type of variation encountered, in the present data, corresponds to the 
distinction between the advertiser's presumed 'strategy' and 'technique', respectively (Rotzoll 1985: 100). 'Strategy' basically involves the decision about what is to be said, whereas 'technique' involves how it is said, the implementation of the advertising strategy. The differences encountered in the present data will be presented, below, along these lines.

\section{THE DATA}

The set of the 55 English-Greek ad pairs examined ranges from items advertising cosmetics, watches and tobacco to cars, airlines and paper copier machines, i.e. products which consumers have 'high involvement' with, as opposed to 'low-involvement' products like food, household items, liquor, candy etc. ${ }^{2}$

\subsection{The Strategy}

'Strategic' decisions (what is to be said) in a target version of translated data can only marginally differ from source version strategic decisions. Translated material is not generally considered the best type of data for exploring original production preferences (Toury 1995), anyway. Thus, content and content organization are rather rarely interfered with in the present set of data $(10 \%)$, but when they do, the modifications may depict specific cultural norms.

In TT1, signed products, like a TAG-HEUER watch, are presented as a promise for social distinction and recognition. By contrast, in the source version, it is the qualities (resistance, precision, and endurance) which are associated with the wearer, rather than the impact of the brand sign on the social surrounding.

ST1 DON'T CRACK UNDER PRESSURE

TAG-HEUER watches; resistance, precision and endurance-qualities found in those who thrive for pressure.

The 4000 automatic series with double protection screw-in crown is water-resistant to 200 meters. It features a unidirectional turning bezel and scratch-resistant sapphire crystal.

TAG-HEUER - SWISS MADE SINCE 1860.

(Newsweek 28.3.1994)

(emphasis added)

TT1 DON'T CRACK UNDER PRESSURE

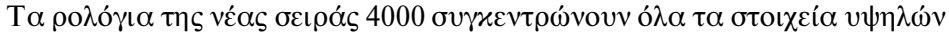

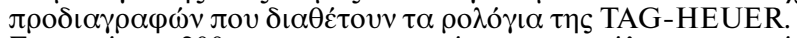

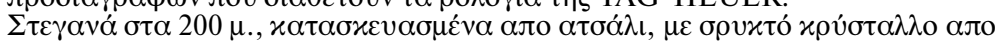

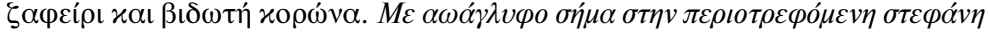

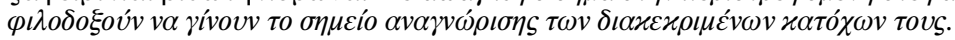

TAG-HEUER - SWISS MADE SINCE 1860.

(4 Trohoi June 1994)

(DON'T CRACK UNDER PRESSURE

The 4000 new series watches have every high quality feature that TAG-HEUER watches exhibit. Water-resistant to $200 \mathrm{~m}$., made of steel, with mineral sapphire crystal and screw-in crown. With the brand sign in relief on the turning bezel, they aspire to become a reason for recognition, for their distinguished beholders.

TAG-HEUER - SWISS MADE SINCE 1860.)

(emphasis added)

Rearranging text fragments in the target version may also conform to cultural considerations about priorities. In TT2, there is a particular view expressed as to whether appearance can be given priority over health; a rearrangement of the product advantages, in the target version, suggests that priority is to be given to health issues (part b: no ammonia --> no danger to the hair) over appearence (part a: natural looking color and 
brilliant shine). Besides, highlighting the function of the source subheadings as 'innovation announcing', in the target version, contributes to making the structure of discourse easily recognizable.

\section{ST2 CASTING - L'Oréal}

IT'S BRILLIANT

Casting blends a contemporary tone with your own for natural looking color and brilliant

a shine, with no noticeable roots.

IT'S GENTLE

No ammonia and low peroxide make it gentle as can be. You can even color the same

b day you perm.

IT'S EASY

Just go click for shining, natural looking color...

(Glamour March 1995)

(emphasis added)

TT2 CASTING - L'Oréal

H КАINOTOMIA $\Sigma T H N$ АПААОТНТА

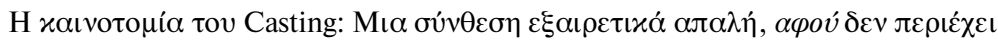

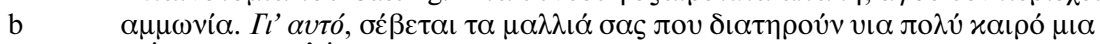
$\alpha \pi i ́ \sigma \tau \varepsilon v \tau \eta ~ \alpha \pi \alpha \lambda o ́ \tau \eta \tau \alpha$.

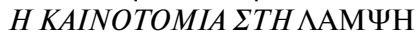

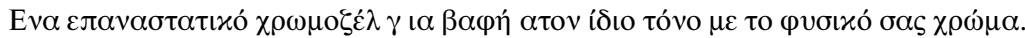

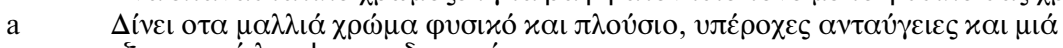

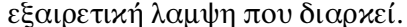

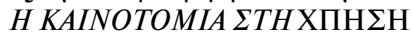

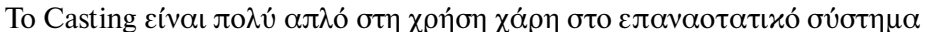
APPLICOLOR...

(Marie Claire May 1994)

(INNOVATION IN SOFTNESS

An extremely gentle composition since it does not contain ammonia. That's why it

b respects your hair which stays incredibly gentle for a long time.

INNOVATION IN BRILLIANCY

A revolutionary color-giving substance for a hair tone identical to your own natural

a one. It gives hair a natural looking and rich color and an extraordinary shine that lasts. INNOVATION IN THE USE

Casting is very simple in it's use due to the revolutionary system APPLICOLOR...)

(emphasis and capitalization added)

A second point of interference in terms of strategic decisions regulating content, is that there is a tendency for humour to disappear in the target advertisements. Rules and myths in advertizing are said to be product-bound (Schudson 1993: 76). Volkswagen, for instance, was the first to use humour and self-mockery in advertisements. The present data indicate that they are culture bound, as well. In TT3 and TT4, the humourous effect created in the source versions has been completely disregarded.

ST3 HYUNDAI ACCENT

The new Hyundai Accent has something you wouldn't expect to find in a family car. Just about everything.

And you could find something else inside it that you didn't expect. You. (What car? March 1995)

(emphasis added)

TT3 HYUNDAI ACCENT

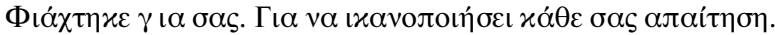
$\cdots$ 


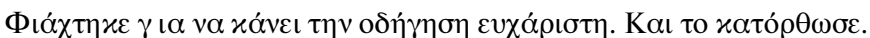

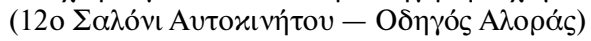

(It has been made for you. In order to satisfy every demand of yours.

It has been made to make driving pleasant. And it has achieved this.)

ST4 DELTA FLY TO AMERICA FROM MORE EUROPEAN CITIES THAN

(emphasis added)

ANYONE ELSE

... So we're big, but are we beautiful?

Well, we get our fair share of fan mail, but it's the letters we don't get that MIGHT

a interest you.

According to the US Department of Transportation, Delta received fewer complaints than any other American international carrier. (And this from a nation that really likes to complain.)

b It's a poll we've been glad to come bottom of every year since $1974 \ldots$. (Newsweek 5.12.94) (emphasis added)

TT4 DELTA AIR LINES. KAMMIA A $\Lambda$ H AEPOПOPIKH ETAIPIA $\Delta$ EN ПETAEI АПО TO $\Sigma$ Е $\Sigma$ EYPQПАIKЕ $\Sigma$ ПО $\Lambda$ ЕI $\Sigma$ ГIA АMЕРIKH

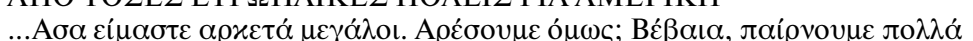

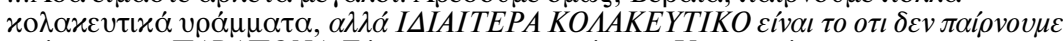

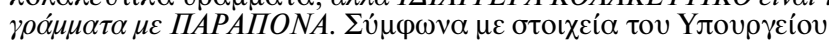

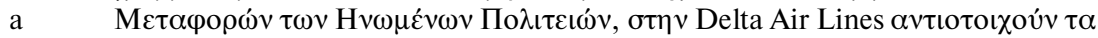

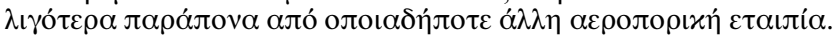

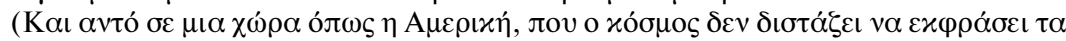

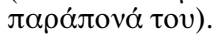

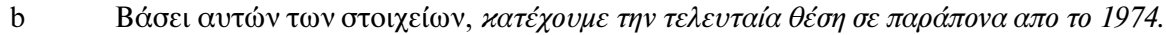

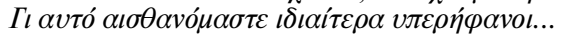

(To Lima 16.10.94)

[NO OTHER AIRLINE FLIES FROM SO MANY EUROPEAN CITIES TO AMERICA

... Therefore, we are big enough. Do people like us, though? Of course we take a lot of fan letters. But what is EXTREMELY FLATTERING is that we take no COMPLAINT

a letters. According to the US Department of Transportation, Delta Airlines receives fewer complaints than any other airline company.

And this, in a country like the U.S., where people do not hesitate to complain). According to this data, we are last on the complaint-receivers' list. That's why we

b feel extremely proud...] emphasis and capitalization added)

In ST4b, there is a denial of expectation technique which creates the humourous effect, namely that people usually like winning polls: they can't be glad to come bottom, which has not been mentioned in TT4b. By contrast, the target version simply states facts without recourse to this denial of expectation technique. In 4a, there is an impact-creating understatement (...letters we don't get that MIGHT interest you...) which has been turned into an explicitly strong statement (...but what is EXTREMELY FLATTERING is that...); besides, there is a suspense-creating technique (the actual referent, 'complaints', is being postponed) leaving the reader to assume, as in ST4a (rather than to be told, as in TT4a), that it is complaints we are talking about.

Similarly, in example 5, Delta Airlines comments on the situation that most airlines do not operate domestic routes in the US, so that passengers are often left to wait a long time until a connection is available for their final destination. A whole text fragment is omitted in the target version, thus completely overlooking the Gricean maxims (quantity (ST5a) \& quality (ST5b)) which create a humourous effect.

ST5 MOST AIRLINES WILL FLY YOU TO AMERICA - DELTA AIRLINES

...You land at terminal one where your airline says 'adios' to you because it does't operate domestic routes in the U.S. Now you are on your own. 
a $\quad$...You find yourself one of those concourse seats that are two inches smaller than your backside and wait.

b And wait. And hope your kids don't grow up before your connecting flight leaves.

Have a nice day...

(Newsweek 3.10.1994 (emphasis added)

TT5 OI ПЕРІ $\Sigma \Sigma$ OTЕРЕ $\Sigma$ AЕРОПОРІКЕ $\Sigma$ ЕTAIPIE $\Sigma \Sigma$ A $\Sigma$ ПАNЕ АП $\Lambda \Omega \Sigma \Sigma$ THN AMEPIKH - DELTA AIRLINES

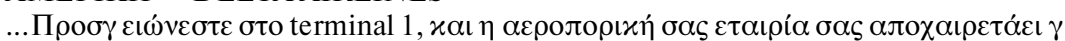

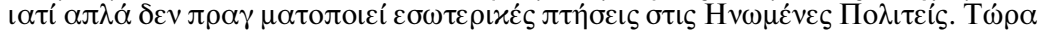

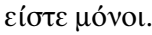

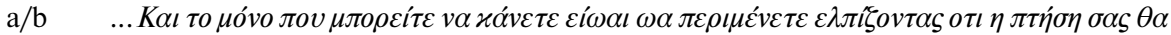

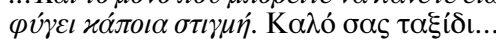

(To Vima 13.11.1994)

[MOST AIRLINES SIMPLY FLY YOU TO AMERICA

...YYou land at terminal one where your airline says 'adios' to you because it does't operate domestic routes in the U.S. Now you are on your own.

$\mathrm{a} / \mathrm{b} \quad$ And the only thing you can do is to wait hoping that your flight will depart some time. Have a nice trip...]

(emphasis added)

A slightly different type of interference with content is that avoiding particular implications following from the source structures, allows for humourous effects compatible with the target readership's cultural models. Air France advertises the rearrangement of space in aeroplanes, so that more space between seats allows more privacy for passengers. The two versions of the advertisement title comment on the possibility of a beautiful lady being seated next to the business traveller in two different ways.

ST6 AIR FRANCE

The chances of her being seated next to you are so slim that you won't regret the extra space between our seats.

(Time International 3.4.1995)

(emphasis added)

\section{TT6 AIR FRANCE}

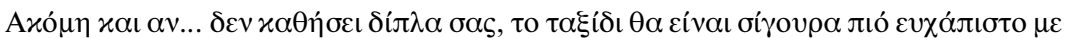

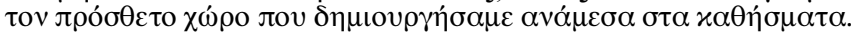

(To Vima 12.4.1995)

(Even if ... she doesn't sit next to you, your trip will definitely be more pleasant with the additional space we have created between seats...)

(emphasis added)

Although the English version almost rejects the possibility of the beautiful lady being seated next to the passenger, thus disrespecting the passenger's self-image by humourously admitting pessimistic aspects of a desirable reality, the Greek version blurs this negative aspect by implicating a more optimistic view: even if she doesn't sit next to you... allows for the implication that there ARE actually chances for the thing to happen, thus contributing to building up the traveller's macho-type image. A humorous effect is preserved but there is no overt admitting of any pessimistic potential, which would need a humourous attitude towards life to be appreciated.

Content is, therefore interfered with in ad translating according to established target conventions. The source material is occasionally rearranged to conform to culturally imposed norms while impression creating techniques are abandoned in favour of informativity.

\subsection{The Technique}

Apart from strategic decisions, which result in interferences in terms of content, there are certain linguistic choices in advertising, as in all media, which 'regulate' the rela- 
tionship the ad constructs between advertiser and consumer. In fact, the construction of advertiser-consumer relationship is the first of the three dimensions of the ideological work of advertising discourse suggested in Fairclough (1989). This is the 'building relations' dimension - contrasted to the 'building images' and 'building the consumer'(1989: 199) ones, which rather relate to 'strategy' adopted by the advertiser (see 1.1).

In the two versions of the present data, the difference in the relationship constructed between advertiser and consumer, is realized through two sets of modifications introduced in the target version: on the one hand, there is a set of modifications which could have been expected, because they have systematically appeared in other English to Greek translated media discourses, and, on the other, there is a set of modifications introduced in the Greek version which is contrary to modifications observed elsewhere in the English to Greek translation practice.

The expected set of modifications observed in the Greek version of the ads examined involves:

- raising the degree of certainty as far as the force of promises, predictions and suggestions are concerned, by silencing modal operators of uncertainty (TT7/8), modifying the force of utterances (TT9), or preferring coordinative contrastive connections over subordinative ones (TT10);

- enriching the cohesive network of the target version (TT9/11/12);

- enriching the evaluative texture of the target version (TT10/12/14/18c).

In TT7/8, for instance, the degree of certainty on the part of the advertiser with respect to the prediction and promise made is raised, by rendering modal structures of probability and possibility in terms of present and future tenses, in Greek, whereas, in TT9, questioning is replaced by reassuring.

ST7 GEORGE BASS'S ROLEX TRAVELS BACK 33 CENTURIES

...Depths of 150 feet are unlikely to trouble a watch which is perfectly at home 1,000 feet below the surface...

(Newsweek 1995)

(emphasis added)

TT7 TO ROLEX TOY GEORGE BASS TA $\Xi I \Delta$ EYEI 33 AI $\Omega N E \Sigma \Pi I \Sigma \Omega \Sigma T$ TO XPONO

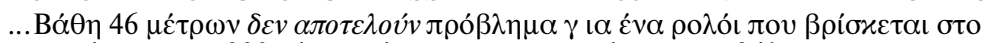

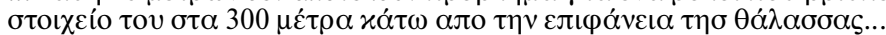

(4 Trohoi 1995)

[...Depths of 46 metres are not a problem for a watch which is perfectly at home at 300 metres below the surface of the sea...]

ST8 ADVANCED NIGHT REPAIR - Estée LAUDER

(emphasis added)

Now the most revolutionary complex we've ever created. And we can prove it.

...And help prevent environmental damage: ultraviolet rays and free radicals that can cause as much as $80 \%$ of premature aging.

...While you sleep, it will replenish your skin's natural protectants,...

...After ten weeks, you could see a $40 \%$ reduction in the appearance of little lines;...

(Vogue April 1994)

(emphasis added)

TT8 ADVANCED NIGHT REPAIR - Estée LAUDER

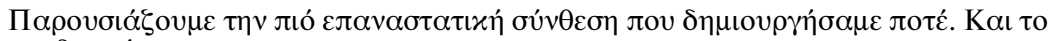
$\alpha \pi \circ \delta \varepsilon เ \varkappa v$ v́ouน.

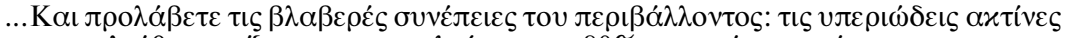

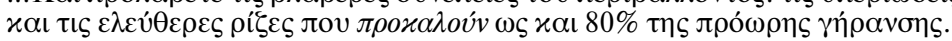

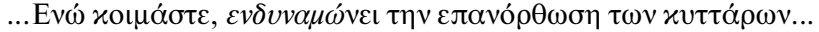

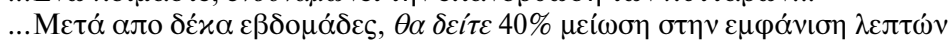
$\lambda \rho \alpha \mu \mu \omega v, \ldots$

(Madame Figaro February 1995) 
[We're introducing the most revolutionary complex we've ever created. And we prove it. ...And prevent the harmful consequences of the environment: ultraviolet rays and free radicals which cause as much as $80 \%$ of premature aging.

...While you sleep, it replenishes...

...After 10 weeks you will see a $40 \%$ reduction in the appearance of little lines,...]

ST9 ADVANCED SUNCARE - Estée LAUDER

(emphasis added)

Are you fully covered?

Relax.

Advanced Suncare protects you against...

Advanced Suncare even moisturises and hydrates during and long after your time in the sun...

(Marie Claire June 1994)

(emphasis added)

TT9 ADVANCED SUNCARE - Estée LAUDER

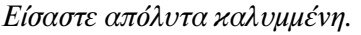

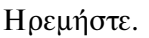

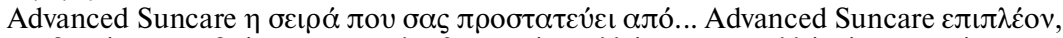

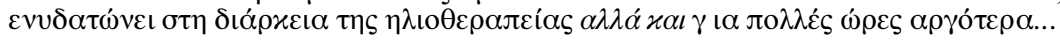
(Marie Claire Aug. 1994)

(You are fully covered.

Relax.

Advanced Suncare is the line which protects you against...

Advanced Suncare even moisturizes during sunbathing but also a long time afterwards...)

(emphasis added)

Preferring coordinative structures over subordinative ones, as in TT10 (ó $\mu \omega \varsigma$ (:however) is preferred over while), has the effect of creating a sharper contrast by highlighting the predominant part of the conjunction (Sidiropoulou 1992).

\section{ST10 WHY EXPLORERS ARE WILLING TO STAKE THEIR LIVES ON A}

\section{ROLEX}

...The extraordinary process that goes into making a Rolex Oyster helps explain why it has accompanied explorers to the heights of Everest and below the frigid waters of the Arctic.

While there are many timepieces people count on for the time, there is but one timepiece they trust with their lives. Rolex.

(Newsweek 1995)

(emphasis added)

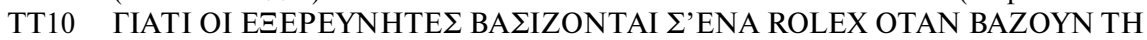
Z $\Omega$ H TOY $\Sigma \Sigma$ E KIN $\triangle$ YNO

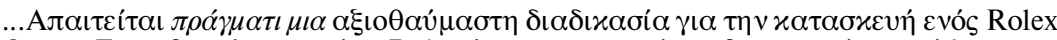

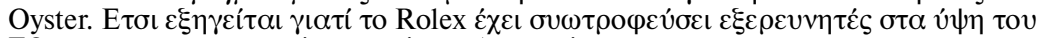

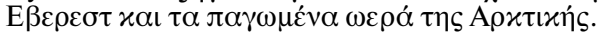

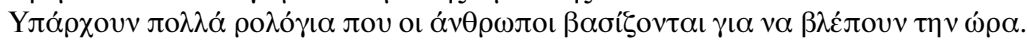

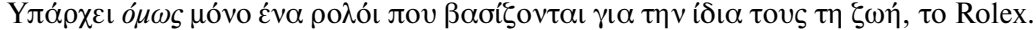
(4 Trohoi 1995)

[An extraordinary process is indeed necessary for making a Rolex Oyster. This helps explain why Rolex has accompanied explorers to the hights of Everest and below the frigit waters of the Arctic.

There are a lot of watches that people count on to know the time. There is however only one watch they trust with their lives, Rolex.]

(emphasis added)

Highlighting contrasts, and other cohesive links, is another widespread type of interference, not only in ad translation, but in press news translation in general (Sidiropoulou 1994). There is a tendency on the part of the translator to enforce a stronger version of the oppositional view of the world generally adopted in the media, by explici- 
tating implicit contrastive shifts in translation. Such a tendency is obvious in TT11 and TT12 (see also TT9).

ST11 COLGATE - PLATINUM

What do you get out of a tube of Platinum? Let's see. Tartar control. Fresh Breath.

Fluoride for cavity protection. And mild safe whitening system with an advanced formula...

(DMB \& B 1994)

(emphasis added)

TT11 COLGATE - PLATINUM

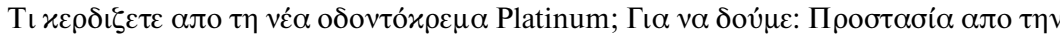

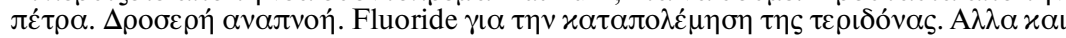

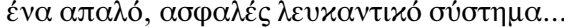

(DMB \& B 1994)

[What do you get out of a Platinum toothpaste? Let's see: Tartar control. Fresh breath. Fluoride for cavity protection. But also a mild safe whitening system...)

ST12 ROUGE FOREVER - HELENA RUBISTEIN

(emphasis added)

For the first time, a lipstic that delivers non-stop colour and continuous hydration... This technologically advanced formula...

(Marie Claire Oct. 1993)

(emphasis added)

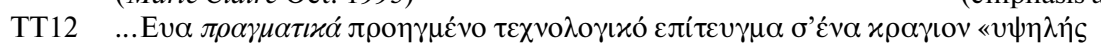

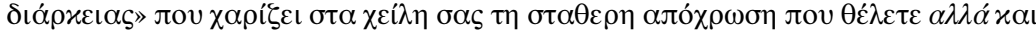

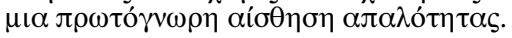

(Marie Claire Aug. 1994)

[A truly advanced technological achievement in a lipstick that delivers the non-stop colour you want but also a unique sense of gentleness.]

(emphasis added)

The contrastive shifts preferred in the persuasion strategy in Greek are not always supported by contrastive connectives. In TT13, the contrast creating intention of the translator made him/her combine information (I wash my hair every day...) which stands in a contrastive relationship to the rest of the discourse.

ST13 NEUTRALIA DERMOPROTECTEUR - GARNIER

..."My skin feels softer, smoother and moisturised"... (Marie Claire July 1994)

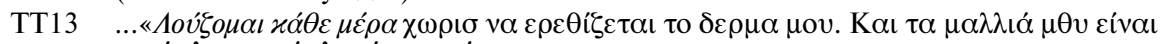

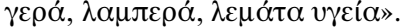

(Marie Claire May 1994)

(..."I wash my hair every day without my skin becoming irritated. And my hair is strong, bright, healthy".)

(emphasis added)

Another expectable interference, on the part of the translator, is enriching the evaluative texture of the target discourse. This has also been observed elsewhere in media translation and was said to be modifying the text-type, by enforcing the argumentative quality of the discourse. In TT12, there is an evaluative element been added (indeed), which is absent from the source. Similarly, in TT14, the item added, xió $\lambda$ s (:already), implies that the modified adverbial phrase should be considered an early point in the

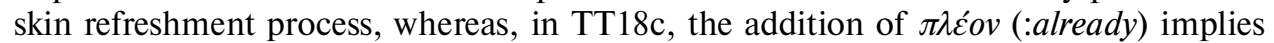
that the skin has long enough suffered the damaging effects of the environment.

ST14 EXPRESSIVE - Lancôme

...This cool, pale blue fluid immediately refreshes and smoothes, actively reducing fine lines, pufiness and dark circles...

(She Feb. 1995)

TT14 EXPRESSIVE - Lancôme 


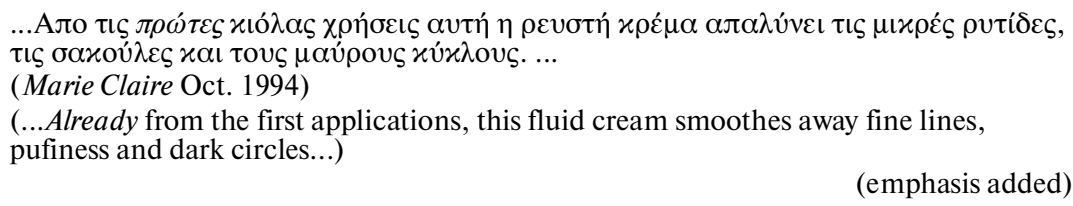

These choices, which are more or less expected, create a stronger directness effect with respect to the relationship between producer and target consumer. However, there are certain distancing devices in the target version, which are not very commonly employed in English to Greek media translation, namely,

- avoiding imperative sentences, and

- silencing first and second person pronouns.

Direct addresses of audience members with you are among the textual features widespread in advertising discourse in English (Fairclough 1989: 205): they create a 'synthetic personalization of the audience member' implying an individual addresser. In the Greek version of the data, imperatives and first/second person pronouns are occasionally avoided.

Although instances of the use of imperative in the target version ARE present in the data $^{3}$, there are a number of instances where the source imperative form has been avoided in Greek.

ST15 Lancôme

Feed your skin with vitamins.

BIENFAIT TOTAL ...

(Marie Claire April 1995) (emphasis added)

TT15 Lancôme

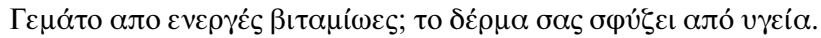
BIENFAIT TOTAL ...

(ELLE April 1995)

(Full of active vitamins? your skin is extremely healthy.)

ST16 Lancôme

(emphasis added)

Liberate your skin.

MAQUI-LIBRE

Skin-liberating makeup natural wear. SPF $15 .$.

(Cosmopolitan Feb. 1995)

(emphasis added)

TT16 Lancôme

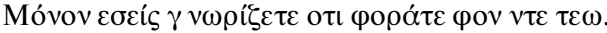

MAQUI-LIBRE

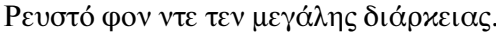

(Marie Claire Mar. 1995)

[Only you know that you have make-up on.

MAQUI-LIBRE

Long-lasting fluid make-up... In brief, an achievement.]

(emphasis added)

The use of the imperative mode is very common in advertising in English (Dyer 1982: 139). Avoiding an imperative in favour of expository (rather than argumentative) devices - i.e. description is preferred over exhortation here - is reducing the immediacy of the advertiser-consumer relationship, thus creating distance. 
Another distancing device used is avoiding first and second person pronouns. In TT17, these pronouns have been rendered by nominalizations (evolution) and intransitive forms (went on).

ST17 GILLETTE SENSOR EXCEL

...We started with Sensor's spring-mounted twin blades that adjust to your face.

Then, we developed a remarkable innovation called microfins and placed them ahead of the blades...

(Automobile April 1995)

(emphasis added)

TT17 GILLETTE SENSOR EXCEL

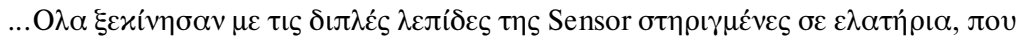

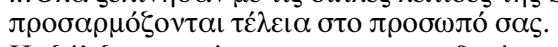

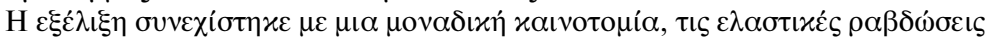

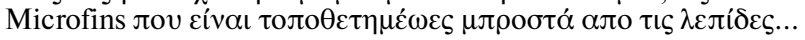

(Ependytis 18.3.95)

([It all started with Sensor's spring-mounted twin blades that adjust perfectly to your face.

The evolution went on with a unique innovation, the Microfins... placed ahead of the blades]

(emphasis added)

Furthermore, in TT18, a second person pronoun, has been replaced by an indefinite pronoun (18a), a second person possessive adjective has been replaced by the generic use of the definite article in Greek (18c) and indefiniteness has been preferred over deixis (18b)

ST18 VERITE - Estée LAUDER

a We used to believe that if you have sensitive skin, you have it forever. Now, there is a new truth. Sensitive skin can become...

b The secret to Verite's effectiveness is Calming Fluid. This unique restorative fluid is a peacemaker for sensitive skin.

c $\quad$...Your skin will be better able to resist the irritating - and damaging effects of the environment and stress. At last, your sensitive skin can live in peace... (ELLE March 1995)

emphasis added)

TT18 VERITE - Estée LAUDER

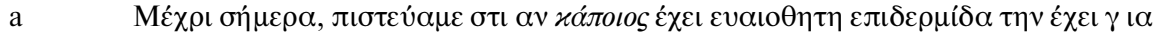

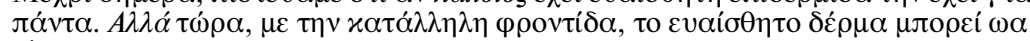
rível...

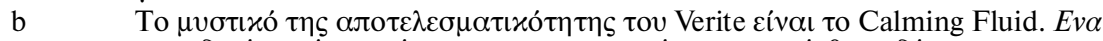

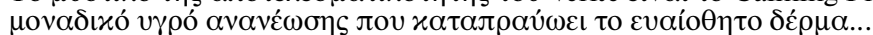

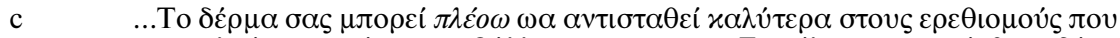

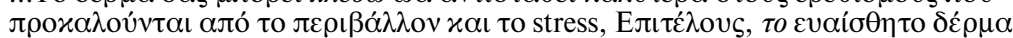

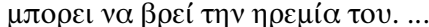

(ELLE March 1995)

(Up to now, we used to believe that if someone has a sensitive skin s/he has it forever.

a But now, with the proper care, sensitive skin can become...

The secret to Verite's effectiveness is Calming Fluid. $A$ unique restorative fluid which

b is a peacemaker for sensitive skin...

Your skin can already better resist the irritation caused by environment and stress. At

c last, sensitive skin can live in peace...)

(emphasis added)

It is indefiniteness and abstraction, that is, occasionally preferred over definiteness and informativity (see also ST/TT10). This is a rather unexpected tendency in media translation. In news headline translation (Sidiropoulou 1995b) there was a reverse ten- 
dency observed: the Greek headlines examined were much more information sensitive than impression creating, by avoiding humour and figures of speech.

Another rather unexpected device is the use of comparative forms in the target text, when there is no such indication in the source version. The use of comparatives could have been compatible with the evaluative tendency observed, but this has been disregarded elsewhere, in media translating. In press news translation, for instance, comparatives used in time reference were omitted in Greek (Sidiropoulou 1995c) because prominence was given to facts rather than accuracy, in time specification. In advertisement translation, although the use of comparatives does seem to pose unnecessary burden on ad processing, it is occasionally preferred over other source structures, evidently, because of the competitive nature of the activity.

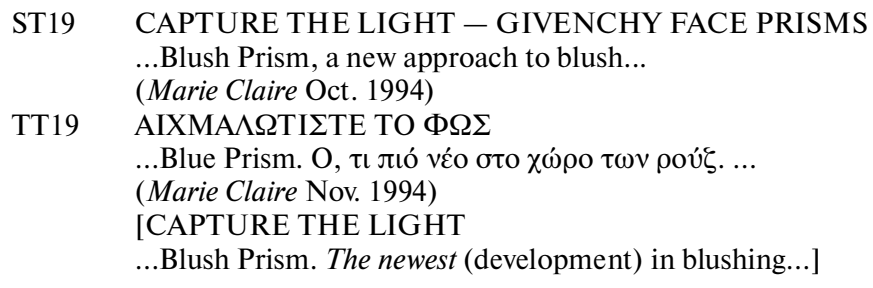

(emphasis added)

Advertisements are a ripe object for analysis. The analysis of advertising may not substitute for an understanding of the economic, political, social and cultural forces that give rise to it, but ads are a vivid body of evidence about the consumer's profile in the social situation and the relationship constructed between consumer and advertiser. Howevers, translated versions of ads may not be as informative about cultural preferences as a prototype body. The analysis of a translated versions of ads can provide reliable evidence about the fairly strong target cultural preferences with respect to the structure of advertising discourse and the consumer's profile, evidence which, if disregarded, would have serious consequences regarding appropriacy of the target situation.

\section{DISCUSSION}

The 55 English-Greek pairs of advertisements examined showed differences in both content and the linguistic devices employed.

In terms of content, the structure of content organization was highlighted by addition of subheadings or explicating the key functions of utterences. Furthermore, the Greek version of the data is more information sensitive than impression creating since humourous effects or suspense-creating techniques are avoided and understatements are rendered in terms of strong statements. Similarly, social constraints are respected since taboo issues like admitting a pessimistic potential about a desired reality is avoided, in Greek, thus implicating character types compatible with target cultural models.

In terms of the linguistic devices employed, there are phenomena which are also interferred with, in the rest of the media, like the degree of certainty with respect to certain speech acts, the cohesive, and particularly the contrastive, network or the degree of evaluative texture of discourse. Furthermore, there are phenomena which are contrary to what is generally observed in English to Greek media translation. For instance, there is a tendency for imperatives, definiteness and first/second person pronouns to be avoided in the target version. These devices are favoured elsewhere in 
social situations in Greek, contrary to English. It is assumed that these distancing devices are employed in advertising in order to ensure the appropriate social distance between producer and consumer which is reduced by the use of the devices which maximize directness. As Greek distinguishes between singular and plural forms of address, distancing is also supported by the plural (rather than singular) second person addresses used throughout the target version. The producer does sound certain about what $\mathrm{s} / \mathrm{he}$ is promising, suggesting or predicting. However, the persuasive strategy in Greek requires more distance to be ensured between producer or consumer which would make the producer sound less biased and would allow the consumer more mental space to process the information offered. It is as if the producer presupposes that the consumer is going to take up the role of the denier and is, therefore, prepared to leave space for objections.

Maximizing the distance between advertiser and consumer could be seen as an effort for the target advertising discourse to be kept within the one-way public discourse of the media rather than become a two-way, face-to-face discourse. Although advertisements are part of media discourse, there are different rules operating with respect to the politeness strategy employed cross-culturally. For instance, in press news translation, there is a stronger tendency for the interpersonal distance between producer and addressee to be minimized in the target version. On the other hand, in advertisement translation, the translator is occasionally less willing to adopt this distance minimizing technique. Furthermore, part of what is not rendered, in ad translating, are the impression-creating elements in favour of informativity and the producer-addressee distanceminimizing techniques. Informativity is favoured in news headline translation (Sidiropoulou 1995b), whereas the distance maximizing tendency has not been observed elsewhere in media translation.

As mentioned above, rules and myths in advertising are said to be product-bound (Schudson 1993: 76). An instantiation of this, in the present data, is the fact that humour has been employed in airline advertising (TT6), but not in cosmetics or watch advertising. Similarly, there is a non-uniform manner of translator interfering throughout the data. With respect to this non-uniformity of behaviour in English-to-Greek ad translation, the question arises as to whether the translator's behaviour varies according to the type of product advertised. This would not be surprising because in 'soft-sell' approaches (perfumes, cosmetics, beers, liquor) impression is of greater importance than information (Rotzoll 1985: 102/104), whereas in the 'hard-sell' school (eg. office equipment) the advertiser assumes the addressee to be more information sensitive, and thus, produces ads heavy on facts.

In the present data, the types of interferences observed have been distributed over the types of products advertised. It appears that cosmetics are the most tolerant product type with respect to the number of modifications introduced by the translator. It is the product type which allows the unexpected set of modifications in media translation. Table 1 shows the distribution of a selected set of interference types encountered in this set of ad translating data over four product types. Strategic and expected technical decisions in discourse construction are - to some extent - observed in all product types. By contrast, the unexpected set of modifications are associated with cosmetics rather than any other product type.

It is shown that, within the same genre, the translator's behaviour fluctuates with respect to the product type advertised. No matter what reasons impose such a non-uniform translation strategy in English-to-Greek advertising, translators should be made aware that there may be genre-internal types of variation which govern translation practice. In the case of advertising, the differing translator behaviour may be due to fac- 
tors associated with potential readers or the product itself. For instance, how the product or service is priced may affect how advertising is used: in some cases advertising is used to promote prices, in others it may be used to promote price competition suggesting that the brand rather than the price should be the crucial factor (Rotzoll 1985).

\begin{tabular}{|l|c|c|c|c|}
\hline Modifications & cosmetics & watches & airlines & cars \\
\hline (STRATEGIC) & + & + & & \\
content information (modified) & + & + & + & + \\
content (reorganized) & + & + & + & + \\
humourous effects (modified) & - & - & + & + \\
\hline (TECHNICAL - EXPECTED) & & & & \\
certainty (raised) & + & + & \pm & + \\
contrasts (highlighted) & + & \pm & \pm & \pm \\
evaluativeness (intensified) & + & \pm & \pm & \pm \\
\hline (TECHNICAL - UNEXPECTED) & & & & - \\
imperatives (avoided) & + & - & - & - \\
personal pronouns (avoided) & + & - & - & - \\
definiteness/informativity (av.) & + & - & - & - \\
comparatives (preferred) & + & - & - & \\
\hline
\end{tabular}

Table 1

Product types advertised vs. (selected set of) modifications encountered between source and target versions of English-to-Greek ad translating

\section{Notes}

1. An early version of this paper was presented at the 2 nd International Conference of the Hellenic Association for the Study of English, organized by the Department of English Language and Literature, School of Philosophy, University of Athens, March 28-April 1, 1996.

2. The study is restricted to that part of the data which does not pose any special doubt as to whether the Greek version examined is a translation of the one traced from the English press. Pairs of ads with identical visuals but substantial differences in the configuration or content have not been included in the data. The products advertised by the ads examined are appended.

3. There are few instances in the data where imperatives are preferred, in Greek, over nominalizations and passive forms, but the reverse phenomenon exposed here is absent elsewhere.

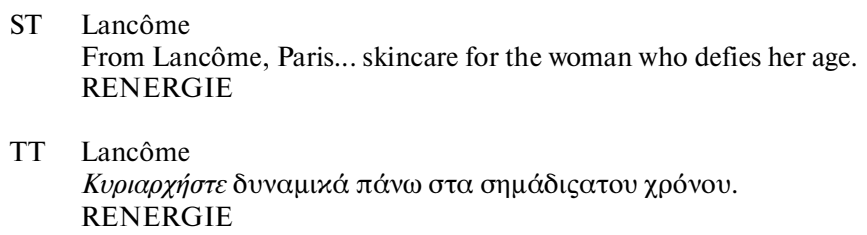

\section{REFERENCES}

DYER, Gillian (1982/87): Advertising as Communication, Studies in Communication Series, London, Methuen.

FAIRCLOUGH, Norman (1989): Language and Power, London, Longman.

ROTZOLL, Kim (1985): "Advertisements", T. van Dijk (Ed.), Discourse and Communication, Berlin, Walter de Gruyter.

SCHULDSON, Michael (1984/84/93): Advertising the Uneasy Persuasion, London, Routledge.

SIDIROPOULOU, Maria (1992): "On the connective ALTHOUGH", Journal of Pragmatics, 17, Elsevier Publishers, pp. 202-221. 
SIDIROPOULOU, Maria (1994): Variation in Translation - English vs. Greek, Paroussia Monograph Series, $\mathrm{n}^{\circ}$ 31, Athens University.

SIDIROPOULOU, Maria (1995a): "Abstract Writing: English-speaking countries vs. Greece", Meta, 40 (4), Montreal, PUM, pp. 579-593.

SIDIROPOULOU, Maria (1995b): "Headlining in Translation: English vs. Greek Press", Target, 7 (2), Amsterdam, John Benjamins, pp. 285-304.

SIDIROPOULOU, Maria (1995c): "Time Reference in Translation", Proceedings of the 9th International Symposium on Theoretical and Applied Linguistics, English Department, Aristotle University of Thessaloniki, pp. 61-74.

TOURY, Gideon (1995): Descriptive Translation Studies and Beyond, Amsterdam, John Benjamins.

\section{APPENDIX 1}

The 55 pairs of English-Greek ad versions examined advertise the following products:

\section{COSMETICS}

Dior Svelte - Christian Dior

Mascara Parfait

Skin Perfection

Expressive - Lancôme

Maqui-Libre

Rouge Absolu

Bienfait Total

Neutralia Foam bath - Garnier

Rouge Forever - Rubinstein

Intercell

Fruition - Estée Lauder

Advances Suncare

Resilience

Advanced Night Repair

Verite

Lucidity

Natural Color - Seventeen

Satin Base

Double Active - Vichy

Regenium

Time Stop Gel - Juvena

Under-Cover Agent - Clinique

Turnaround

Casting - L'Oréal

Plenitude - excell - A3

Gilette Sensor Excel

Face Prisms - Givenchy

Platinum - Colgate

TOBACCO

Stuyvesant

CARD

The American Express

\section{WATCHES}

Rolex Oyster - (a)

Rolex Oyster - (b)

Rolex Lady Chronometer

Longines

2000 Series Tag-Heиеr

4000 Series Tag-Heuer

Omega

EQUIPMENT

Paper Copier SF-7320 - Sharp

Paper Copier SF-7850

LaserJet - Hewlett Packard

Deskjet

OS/2 Warp - IBM

Client Server

Power Engineering - Siemens

\section{CARS}

$S A A B 900$ TURBO

Toyota

Alfa Romeo 145

Hyundai Accent

Monroe

\section{AIRLINES}

Delta - (a)

Delta - (b)

Lufthansa

Air France

Olympic Aviation 